\title{
Clinical Study \\ Effect of Intravitreal Ranibizumab in the Treatment of Peripapillary Choroidal Neovascularisation
}

\author{
Hassan Hamoudi and Torben Lykke Sørensen \\ Department of Ophthalmology, Copenhagen University Hospital Roskilde and University of Copenhagen, 4000 Roskilde, Denmark \\ Correspondence should be addressed to Torben Lykke Sørensen, torbenls@dadlnet.dk
}

Received 22 September 2011; Accepted 28 September 2011

Academic Editor: Andrew G. Lee

Copyright ( $) 2011$ H. Hamoudi and T. L. Sørensen. This is an open access article distributed under the Creative Commons Attribution License, which permits unrestricted use, distribution, and reproduction in any medium, provided the original work is properly cited.

\begin{abstract}
Intravitreal ranibizumab therapy is widely used in treatment of subfoveal choroidal neovascularisation (CNV) in age-related macular degeneration. We wanted to study the effect of intravitreal ranibizumab therapy in peripapillary CNV. A prospective recording of treatment outcomes in twelve eyes (12 patients) with peripapillary CNV with intravitreal injections of ranibizumab was performed. The patients received a series of 3 injections $4-6$ weeks apart, and then a new ophthalmic examination was made including OCT and further therapy was given if the peripapillary CNV was still active. Nine patients had idiopathic peripapillary $\mathrm{CNV}$, and in 3 patients it was associated to age-related macular degeneration. Followup had to be at least 6 months. The mean follow-up time was 15.9 (range 9-27) months and the mean number of injections 6.2 (3-10). In 10 patients treatment had resulted in an inactivation of the peripapillary CNV, but 3 of them had reactivation, while 2 patients had no inactivation. Currently, 5 patients are continuous to receive treatment. VA improved in 10 patients. Intravitreal ranibizumab therapy appears to be effective in patients with peripapillary CNV, but in some cases there is repeated reactivation or continuous activity of the peripapillary CNV.
\end{abstract}

\section{Introduction}

The use of antivascular endothelial growth factor (antiVEGF) agents for the treatment of retinal diseases is constantly increasing. Anti-VEGF was primarily introduced for the treatment of age-related macular degeneration (AMD) complicated with a sub- or juxtafoveal choroidal neovascularisation, but its use is now expanding to retinal vein occlusions and diabetic macular edema [1-3].

Peripapillary CNV is rare. Several conditions can cause peripapillary CNV including AMD (the most common cause, $45.2 \%$ of the cases), idiopathic (39.1\%), multifocal choroiditis $(4.3 \%)$, angioid streaks $(2.6 \%)$, histoplasmosis (1.7\%), choroidal osteoma (1.7\%), optic disc drusen $(0.9 \%)$, and congenital disc anomaly $(0.9 \%)$ and has been reported in sarcoid [4]. No randomised or large study has evaluated the efficacy of anti-VEGF on peripapillary $\mathrm{CNV}$ hence standard care for peripapillary $\mathrm{CNV}$ remains argon laser photocoagulation or photodynamic therapy $[5,6]$. However, since anti-VEGF is effective in treating CNV, it seems relevant to treat peripapillary $\mathrm{CNV}$ with anti-VEGF.
Information regarding the efficacy of anti-VEGF on peripapillary $\mathrm{CNV}$ is based on case reports and small case series [7-12]. Overall the results suggest a possible beneficial effect of anti-VEGF on peripapillary CNV, but questions remain regarding the long-term beneficial effect of the treatment, since continuous visual decline, and CNV activity despite treatment has been reported in some patients $[7,12]$.

The purpose of this study was to evaluate the efficacy of ranibizumab in patients with peripapillary CNV.

\section{Methods}

Twelve eyes (12 patients) were included in this study. At baseline all patients underwent an ophthalmic examination including a dilated fundus examination, best-corrected visual acuity (VA) using the early treatment of diabetic retinopathy study (ETDRS) chart, spectral domain optical coherence tomography (SD-OCT) imaging using Heidelberg HRA-Spectralis system (Heidelberg Engineering, Heidelberg, Germany) and fluorescein angiography (FA) as well as 
TABLE 1: Patient characteristics and treatment results. (F: female; M: male). (Central retinal thickness).

\begin{tabular}{|c|c|c|c|c|c|c|c|c|c|c|}
\hline $\begin{array}{l}\text { Patient } \\
\text { number }\end{array}$ & Sex & Age years & Diagnosis & $\begin{array}{c}\text { Onset } \\
\text { ETDRS }\end{array}$ & $\begin{array}{l}\text { Current } \\
\text { ETDRS }\end{array}$ & $\begin{array}{c}\text { Number of } \\
\text { injections }\end{array}$ & Onset CRT & $\begin{array}{c}\text { Current } \\
\text { CRT }\end{array}$ & $\begin{array}{c}\text { Follow-up } \\
\text { months }\end{array}$ & $\begin{array}{c}\text { Current } \\
\text { status }\end{array}$ \\
\hline 1 & F & 80 & Idiopathic & 77 & 78 & 10 & 302 & 235 & 22 & $\begin{array}{c}\text { Continuous } \\
\text { treatment }\end{array}$ \\
\hline 2 & M & 74 & Idiopathic & 65 & 76 & 9 & 291 & 211 & 21 & $\begin{array}{c}\text { Continuous } \\
\text { treatment }\end{array}$ \\
\hline 3 & F & 70 & Idiopathic & 59 & 83 & 3 & 461 & 210 & 14 & Inactive \\
\hline 4 & $\mathrm{~F}$ & 81 & AMD & 65 & 45 & 9 & 486 & 140 & 27 & $\begin{array}{c}\text { Continuous } \\
\text { treatment }\end{array}$ \\
\hline 5 & F & 87 & Idiopathic & 70 & 85 & 3 & 274 & 245 & 18 & Inactive \\
\hline 6 & F & 76 & Idiopathic & 35 & 46 & 3 & 400 & 292 & 23 & Inactive \\
\hline 7 & F & 70 & Idiopathic & 85 & 90 & 9 & 280 & 280 & 17 & Inactive \\
\hline 8 & F & 81 & Idiopathic & 65 & 70 & 6 & 615 & 543 & 9 & $\begin{array}{c}\text { Continuous } \\
\text { treatment }\end{array}$ \\
\hline 9 & $\mathrm{M}$ & 76 & AMD & 65 & 73 & 6 & 348 & 280 & 15 & Inactive \\
\hline 10 & $\mathrm{M}$ & 76 & AMD & 28 & 32 & 5 & 500 & 384 & 9 & Inactive \\
\hline 11 & $\mathrm{M}$ & 28 & Idiopathic & 26 & 47 & 6 & 350 & 322 & 9 & Inactive \\
\hline 12 & $\mathrm{M}$ & 81 & Idiopathic & 72 & 63 & 5 & 307 & 250 & 9 & $\begin{array}{c}\text { Continuous } \\
\text { treatment }\end{array}$ \\
\hline
\end{tabular}

indocyanine green (ICG) angiography to rule out polypoidal vasculopathy was performed. The patients were initially assigned to 3 intravitreal injections of $0.5 \mathrm{mg}$ ranibizumab 4-6 weeks apart.

Approximately, 1 month after the 3rd injection the patients returned for a clinical reevaluation including VA, SD-OCT, and dilated fundus examination. The OCT was both done through the fovea and the optic nerve. Based on signs of activity (intra- or subretinal fluid or retinal haemorrhages) it was decided whether to continue treatment using a variable dosing regimen -1 to 3 injections - or to reevaluate the patient again every 4-6 weeks. The reevaluation consisted of repeated VA, SD-OCT and dilated fundus examinations. We did not use FA to evaluate reactivation.

Informed consent was obtained from all participants and they all agreed to the off-label nature of the treatment. None of the patients had received any other treatment for peripapillary $\mathrm{CNV}$.

\section{Results}

Patient characteristics and treatment results are shown in Table 1 and Figure 1. All patients were Caucasian, with a mean age of 73 years (range: 28-87), 7 females and 5 males. The mean length of followup was 15.9 months (range: 9-27). The mean number of injections with intravitreal ranibizumab was 6.2 (range: $3-10$ ). In patients without obvious signs of drusen and/or changes in the RPE the $\mathrm{CNV}$ was categorized as idiopathic. Nine eyes had idiopathic peripapillary $\mathrm{CNV}$ and 3 eyes had peripapillary $\mathrm{CNV}$ as part of AMD (Figure 2). All patients presented with subfoveal fluid causing a decrease of vision. The mean visual acuity at baseline was 59 letters (range: 26-85) and had significantly improved to 66 letters (range: 32-90) after treatment $(P=0.002$, paired samples $t$-test). Ten out of 12 patients

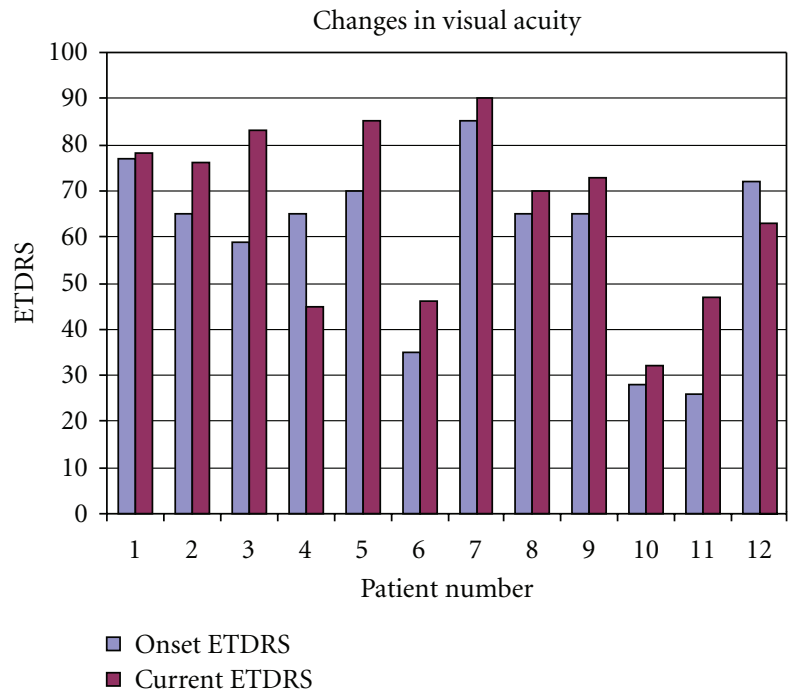

Figure 1: Changes in visual acuity after treatment.

experienced an improvement in VA after treatment while vision declined in 2 patients.

Inactivation after the initial treatment regime with three injections was obtained in 5 patients, and of them 2 patients experienced reactivation after 8 and 16 months, respectively. In 5 other patients inactivation was obtained after 5-10 injections, of them 1 patient had reactivation after 18 months. Two patients had no inactivation and do receive continuous treatment. Currently, 7 patients show no sign of activity of the CNV, while 5 patients are still receiving treatment at the time of followup. In total 10 out of 12 patients experienced inactivation at some point of followup, and of them 3 patients had reactivation. The central retinal thickness (CRT) decreased in all but 1 patients 


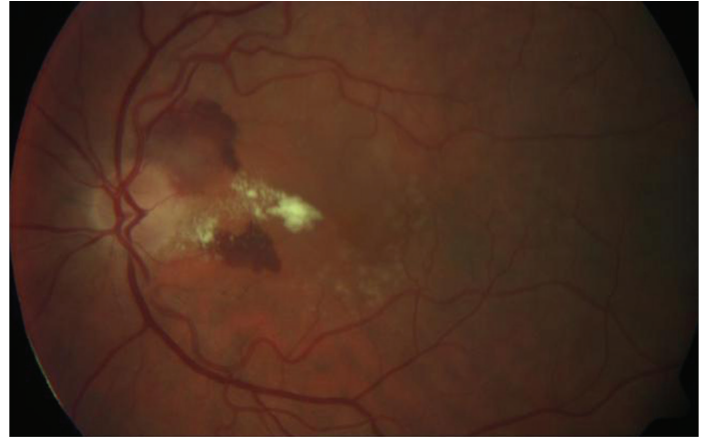

(a)

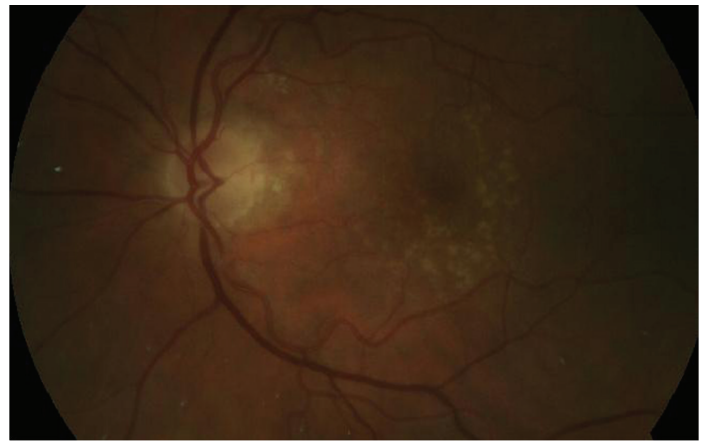

(b)

FIGURE 2: An example of fundus photography showing peripapillary CNV before and after treatment in a patient with AMD (patient $4)$.

(Table 1). All 3 patients with AMD had inactivation after 3 , 5 , and 6 injections, respectively. The patient with 3 injections had reactivation after 16 months. Of the 9 patients with idiopathic CNV, inactivation was achieved in 7 patients, of them 2 had reactivation, and 2 others did not obtain inactivation and do still receive treatment.

\section{Discussion}

Peripapillary $\mathrm{CNV}$ is rare and treatment studies of this condition consist primarily of short case reports and case series treating peripapillary $\mathrm{CNV}$ with either bevacizumab or ranibizumab.

Four reports on the effect of bevacizumab have been published $[7-9,11]$. Two are small case series, 6 eyes and 4 eyes, respectively, and two are case reports adding up to 12 eyes in total with variable aetiologies to the peripapillary CNV $[7-9,11]$. Follow-up ranges from 3 months to mean followup of 13 months. All studies report an initial favourable response to treatment, but in the study with the longest follow-up, inactivity was obtained in five of six eyes, and one eye did not respond to treatment [7]. These findings correspond to our findings where 10 out of 12 patients had inactivation. Even though the findings are similar, there are several differences in our study and the study of Figueroa and coworkers the patients were treated with bevacizumab, mean age was 67.8 years, and mean VA at baseline was 44 letters, and 2 patients had earlier been treated with surgical removal of the neovascular membrane [7]. There is also difference in the length of follow-up in their study compared to ours, since they had a mean followup of 13 months (range 6-16), and 2 of our patients had reactivation after 16 and 18 months of followup.

Only two papers have reported on the efficacy of ranibizumab in peripapillary $\mathrm{CNV}[10,12]$. One is a case series of seven eyes (6 patients) and one is a case report. The case series studied patients with paripapillary CNV of various aetiologies ( 4 angioid streaks, 2 idiopathic, 1 as part of AMD) with a mean followup of 12 months. Ranibizumab was successful in improving VA and resolution of subfoveal fluid was accomplished. [10] The case report studied one patient with sarcoidosis, uveitis, and peripapilliary $\mathrm{CNV}$ and after 12 months of followup there were still signs of activity [12].

Even though peripapillary $\mathrm{CNV}$ in some instances can be watched because of the asymptomatic nature, treatment should be considered when the fovea is threatened. Treatment of peripapillary CNV has recently been reviewed, and generally there is lack of evidence concerning the ideal treatment strategy in patients with peripapillary CNV, even though the theoretical rationale favours treatment with antiVEGF [13].

In our study, we find a tendency towards efficacy of ranibizumab in the treatment of peripapillary CNV. However, complete inactivation of the CNV was only obtained in 7 of 12 patients $(58 \%)$ at the end of followup. In the majority of patients, VA improves and the CRT decreases on OCT. Even though our study has a limited number of patients it is still the largest number of cases and the longest followup so far reporting on the efficacy of ranibizumab in peripapillary CNV. Our findings suggest that ranibizumab is a feasible solution for the treatment of peripaillary CNV, but reactivation and lack of inactivation resulting in a need for continuous treatment are common.

\section{References}

[1] P. J. Rosenfeld, D. M. Brown, J. S. Heier et al., "Ranibizumab for neovascular age-related macular degeneration," The New England Journal of Medicine, vol. 355, no. 14, pp. 1419-1431, 2006.

[2] T. Y. Wong and I. U. Scott, "Retinal-vein occlusion," The New England Journal of Medicine, vol. 363, no. 22, pp. 2135-2144, 2010.

[3] M. Waisbourd, M. Goldstein, and A. Loewenstein, "Treatment of diabetic retinopathy with anti-VEGF drugs," Acta Ophthalmologica, vol. 89, pp. 203-207, 2011.

[4] D. J. Browning and C. M. Fraser, "Ocular conditions associated with peripapillary subretinal neovascularization, their relative frequencies, and associated outcomes," Ophthalmology, vol. 112, no. 6, pp. 1054-1061, 2005.

[5] Macular Photocoagulation Study Group, "Laser photocoagulation for neovascular lesions nasal to the fovea," Archives of Ophthalmology, vol. 113, pp. 56-61, 1995.

[6] B. J. Rosenblatt, G. K. Shah, and K. Blinder, "Photodynamic therapy with verteporfin for peripapillary choroidal neovascularization," Retina, vol. 25, no. 1, pp. 33-37, 2005. 
[7] M. S. Figueroa, S. Noval, and I. Contreras, "Treatment of peripapillary choroidal neovascular membranes with intravitreal bevacizumab," The British Journal of Ophthalmology, vol. 92, no. 9, pp. 1244-1247, 2008.

[8] A. E. Hoeh, K. B. Schaal, T. Ach, and S. Dithmar, "Treatment of peripapillary choroidal neovascularization with intravitreal bevacizumab," European Journal of Ophthalmology, vol. 19, no. 1, pp. 163-165, 2009.

[9] W. Soliman, H. Lund-Andersen, and M. Larsen, "Resolution of subretinal haemorrhage and fluid after intravitreal bevacizumab in aggressive peripapillary subretinal neovascularization," Acta Ophthalmologica Scandinavica, vol. 84, no. 5, pp. 707-708, 2006.

[10] Y. Nochez, M. L. Le Lez, and P. J. Pisella, "Intravitreal injections of ranibizumab in treatment of large peripapillary choroidal neovascularisation," Journal of French Ophthalmology, vol. 32, pp. 25-31, 2009.

[11] U. H. M. Spandau and J. B. Jonas, "Intravitreal bevacizumab for peripapillary classic subretinal neovascularization," Acta Ophthalmologica Scandinavica, vol. 85, no. 3, pp. 340-341, 2007.

[12] S. P. Shah, J.-P. Hubshman, J.-L. Bourges, A. Y. H. Hu, and S. D. Schwartz, "Limited long-term efficacy of intravitreous anti-VEGF pharmoacotherapy in sarcoidosis complicated by peripapillary chorodial neovascular membrane," Acta Ophthalmolologica, vol. 88, no. 6, pp. e243-e244, 2010.

[13] G. Jutley, G. Jutley, V. Tah, D. Lindfield, and G. Menon, "Treating peripapillary choroidal neovascular membranes: a review of the evidence," Eye, vol. 25, pp. 675-681, 2011. 


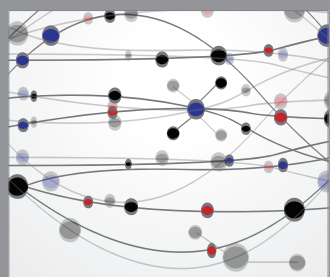

The Scientific World Journal
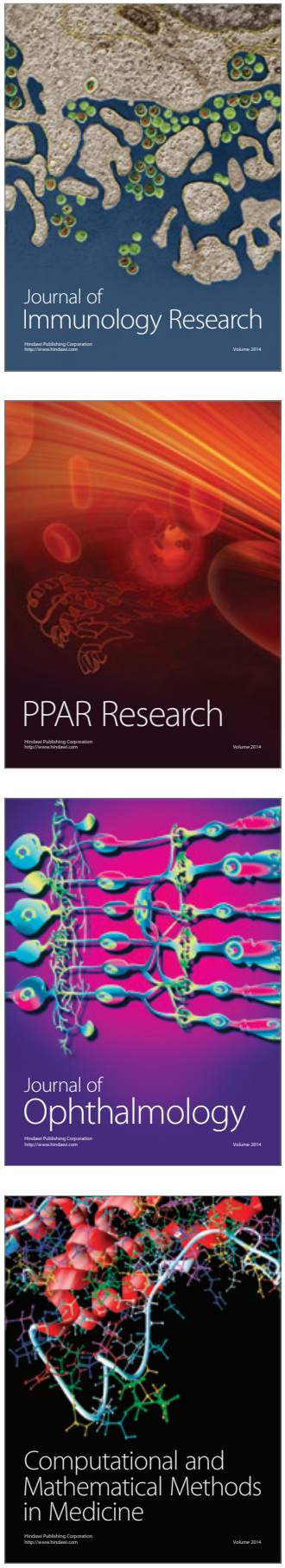

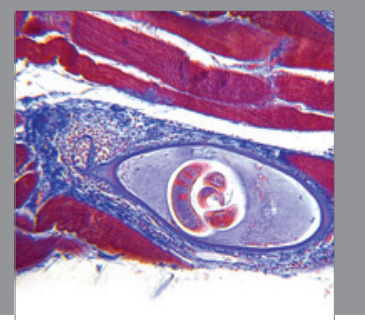

Gastroenterology

Research and Practice
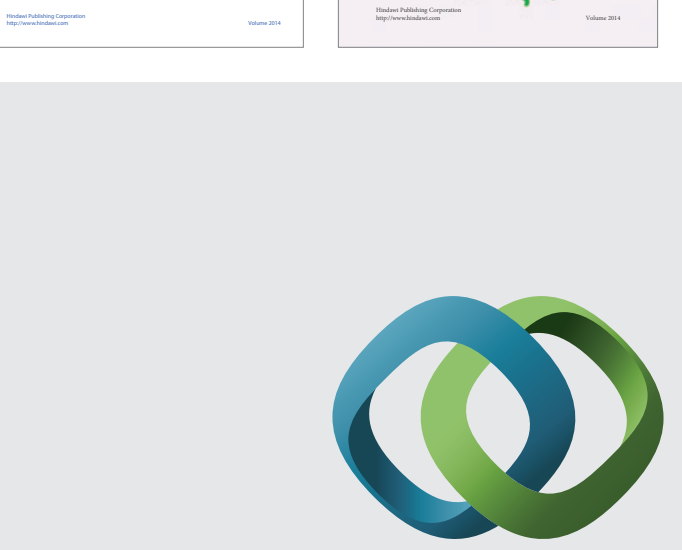

\section{Hindawi}

Submit your manuscripts at

http://www.hindawi.com
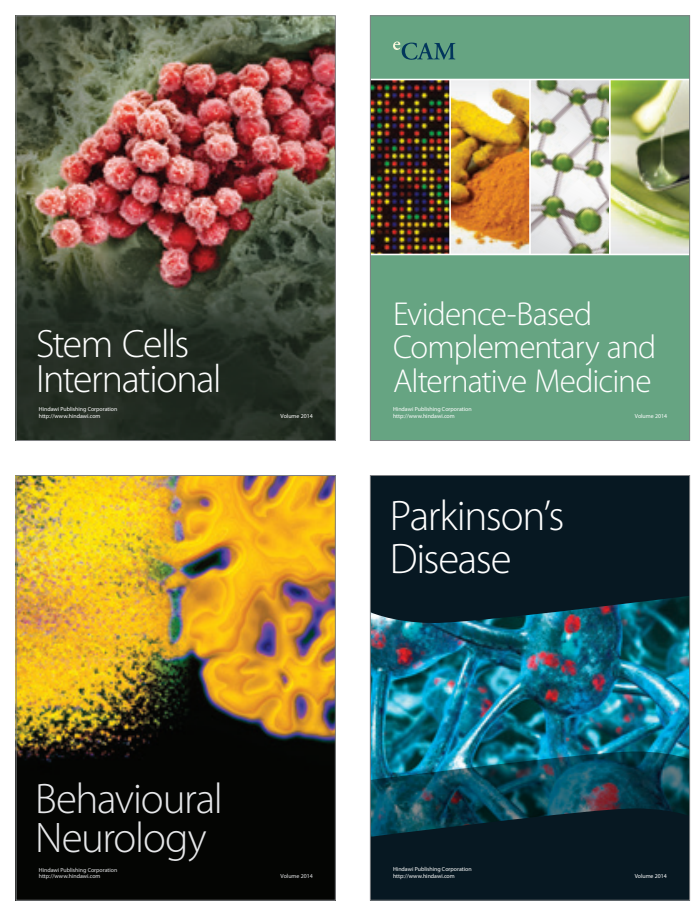

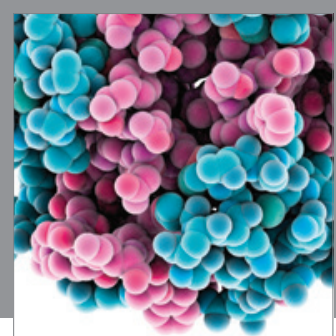

Journal of
Diabetes Research

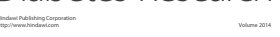

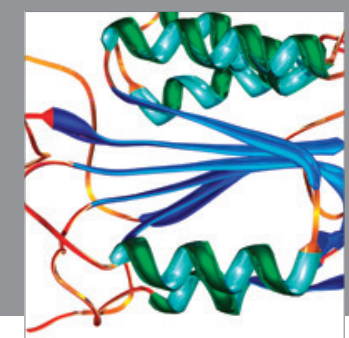

Disease Markers
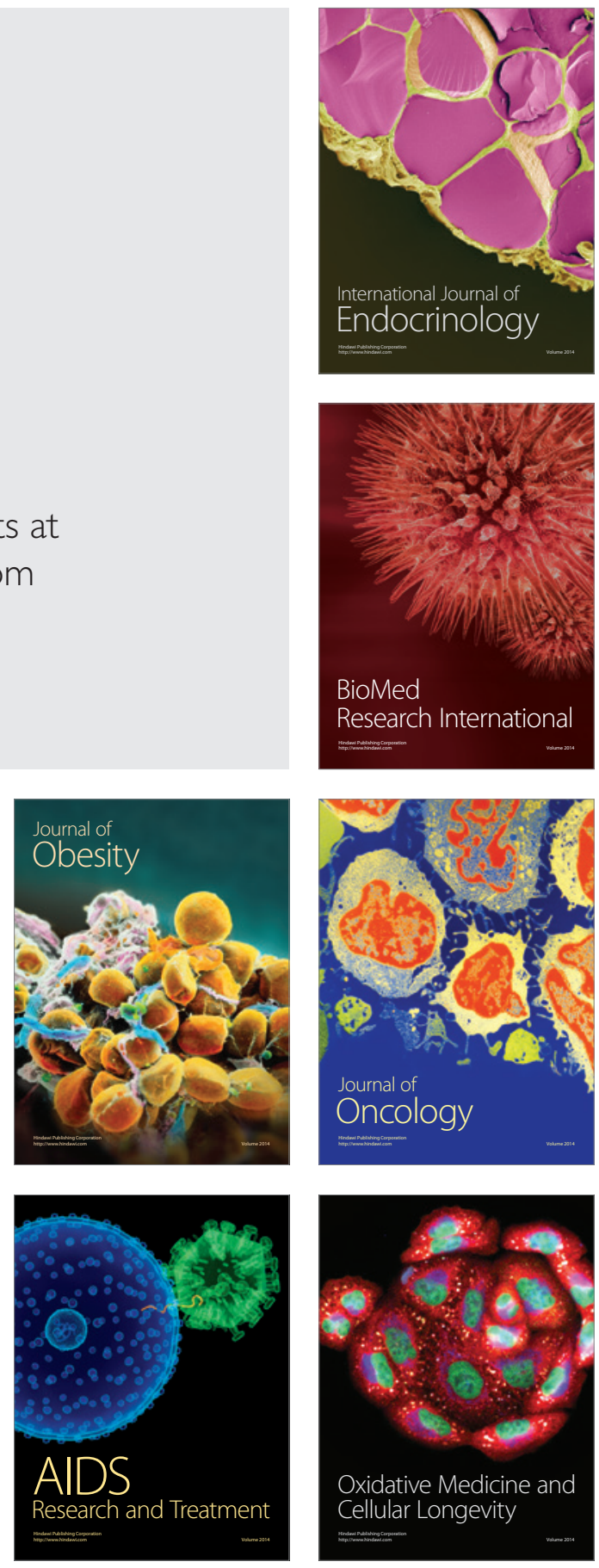